\title{
A Case of J Wave Syndrome Due to Severe Hypercalcemia with Ventricular Fibrillation Storm and Successful Treatment of Isoproterenol Infusion
}

\author{
Masayuki Shiozaki, ${ }^{1}$ MD, Masataka Sumiyoshi, ${ }^{1}$ MD, Haruna Tabuchi, ${ }^{2}$ MD, Hidemori Hayashi, ${ }^{2}$ MD, \\ Hiroshi Tamura, ${ }^{1}$ MD, Kenji Inoue, ${ }^{1}$ MD and Tohru Minamino, ${ }^{2}$ MD
}

\begin{abstract}
Summary
A case of $\mathbf{J}$ wave syndrome with ventricular fibrillation (VF) storm and severe hypercalcemia due to primary hyperparathyroidism is presented. VF storm subsided with an isoproterenol infusion. Prominent $\mathrm{J}$ waves and a Brugada-like electrocardiogram pattern disappeared after parathyroidectomy. Ventricular tachyarrhythmia was not induced during an electrophysiological study. The patient remained asymptomatic up to the 12-month follow-up.
\end{abstract}

Key words: Prominent J waves, Brugada syndrome, Hyperparathyroidism

(Int Heart J 2021; 62: 924-926)

$\mathrm{H}$ ypercalcemia is known to be a cause of $\mathrm{J}$ wave syndrome; ${ }^{1)}$ however, the development of ventricular fibrillation (VF) has been reported in only a few cases. ${ }^{2-4)}$ We experienced a case of $\mathrm{J}$ wave syndrome with VF storm due to secondary hypercalcemia. In addition, we demonstrated for the first time that the intravenous isoproterenol (ISP) was effective not only for the prevention of VF but also for the disappearance of the prominent $\mathrm{J}$ waves.

\section{Case Report}

A 52-year-old man was hospitalized for the examination of fatigue, anorexia, and drowsiness. His family history was unremarkable, with no history of sudden death. He was not taking any medications. On admission, his Glasgow Coma Scale was E4V5M6, but physical examination was unremarkable, except for elevated blood pressure of $158 / 110 \mathrm{mmHg}$. There were no abnormalities of the neck, chest, and abdomen. The electrocardiogram (ECG) on admission showed a sinus rhythm of $66 \mathrm{bpm}$ with a type $1 \mathrm{ST}$ elevation in V1 and type 2 ST elevation in V2 (Figure 1A). The chest X-ray was normal. Blood examination showed a high corrected serum calcium level of $18.3 \mathrm{mg} / \mathrm{dL}$ (normal range: 8.6-10.2 $\mathrm{mg} / \mathrm{dL}$ ) and a markedly elevated intact parathyroid hormone level of $1250 \mathrm{pg} / \mathrm{mL}$ (normal range: $10-65 \mathrm{pg} / \mathrm{mL}$ ), a serum albumin level of $4.8 \mathrm{~g} / \mathrm{dL}$, and normal magnesium $(2.1 \mathrm{mg} /$ $\mathrm{dL})$ and potassium (4.5 $\mathrm{mmol} / \mathrm{L})$ levels. Renal insufficiency was found, with a serum creatinine of $1.80 \mathrm{mg} / \mathrm{dL}$. Magnetic resonance imaging of the brain and a cardiac echocardiogram did not demonstrate any abnormalities.
After hospitalization, combination therapy of forced saline diuresis $(2000 \mathrm{~mL} / 24$ hours $\mathrm{NaCl} 0.9 \%$ and furosemide $40 \mathrm{mg} / 24$ hours) and elcatonin 80 units/day was started. Although the serum calcium level decreased only slightly, from 18.3 to $16.3 \mathrm{mg} / \mathrm{dL}$, his symptoms improved. On the fifth day of hospitalization, when the patient talked with his family, he suddenly lost consciousness because of VF (Figure 2). The VF was successfully converted to sinus rhythm with a single direct current (DC) cardioversion of $150 \mathrm{~J}$. He was transferred to the coronary care unit. VF occurred repeatedly, and DC cardioversion was required several times. The ECG during sinus rhythm showed type 1 ST elevation in V1-3 and prominent $\mathrm{J}$ waves in V4-6 and the inferior leads (Figure 1B). Thus, J wave syndrome including Brugada syndrome was suspected, and ISP was infused intravenously at $0.02 \mu \mathrm{g} / \mathrm{kg} /$ minute. After the infusion of ISP, the ST elevation and J waves disappeared, and the VF storm subsided (Figure 1C). Then, oral quinidine $300 \mathrm{mg} /$ day and cilostazol $100 \mathrm{mg} /$ day were started. After forced saline diuresis, cinacalcet hydrochloride 50 $\mathrm{mg} / \mathrm{day}$, and hemodialysis, the serum calcium level was normalized to $9.4 \mathrm{mg} / \mathrm{dL}$ on the ninth day. Parathyroid ultrasonography showed a hypoechoic nodule at the right upper lobe. Parathyroid scintigraphy with Tc-99m MIBI (sestamibi) showed increased activity in the right upper lobe, and this activity persisted on late images. The patient underwent parathyroidectomy, and the histopathological examination confirmed the tumor was a parathyroid adenoma. Electrophysiological study (EPS) was conducted 3 weeks after parathyroidectomy without medication. Neither ventricular tachycardia nor VF could be induced during the EPS with programmed ventricular

From the ${ }^{1}$ Department of Cardiology, Juntendo University Nerima Hospital, Tokyo, Japan and ${ }^{2}$ Department of Cardiovascular Biology and Medicine, Juntendo University Graduate School of Medicine, Tokyo, Japan.

Address for correspondence: Masayuki Shiozaki, MD, Department of Cardiology, Juntendo University Nerima Hospital, 3-1-10, Takanodai, Nerimaku, Tokyo 177-0033, Japan. E-mail: m.shio1101@gmail.com

Received for publication December 16, 2020. Revised and accepted February 12, 2021.

doi: 10.1536/ihj.20-798

All rights reserved by the International Heart Journal Association. 
A

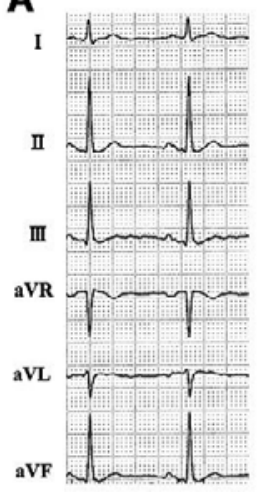

B

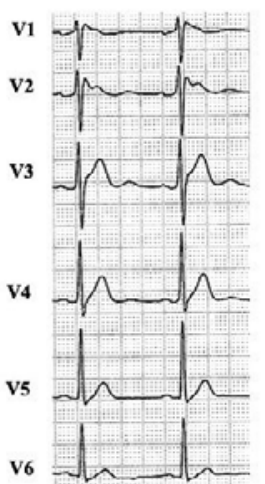

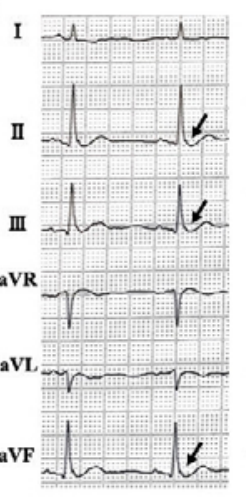

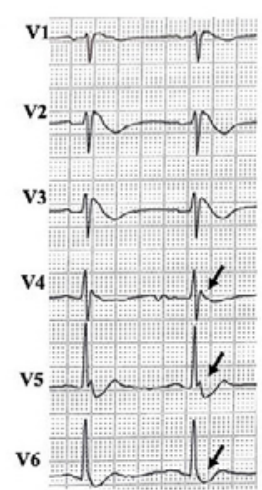

C

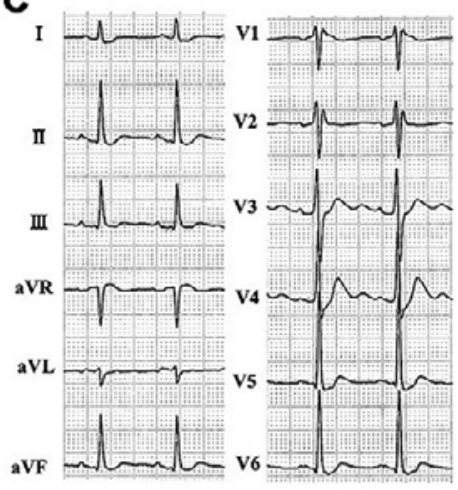

Figure 1. Electrocardiograms (ECG). A: On admission, ECG showing a sinus rhythm with a type 1 ST elevation in V1 and a type 2 ST elevation in V2. B: ECG after defibrillation of VF shows type 1 ST elevation in V1-3, and prominent J waves in V4-6 and the inferior leads (arrows). C: After the infusion of isoproterenol, ST elevation and J waves disappear, and VF storm subsides.

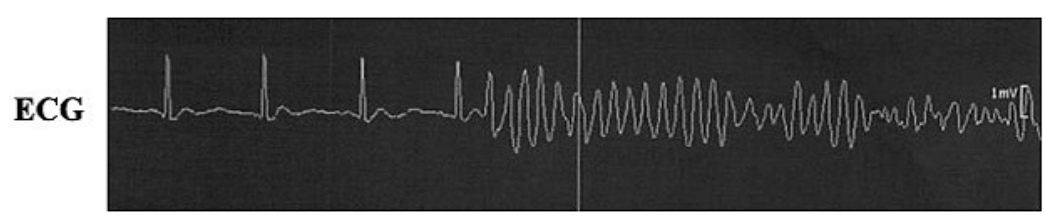

Figure 2. Electrocardiographic monitoring record of ventricular fibrillation.

\section{A Baseline}

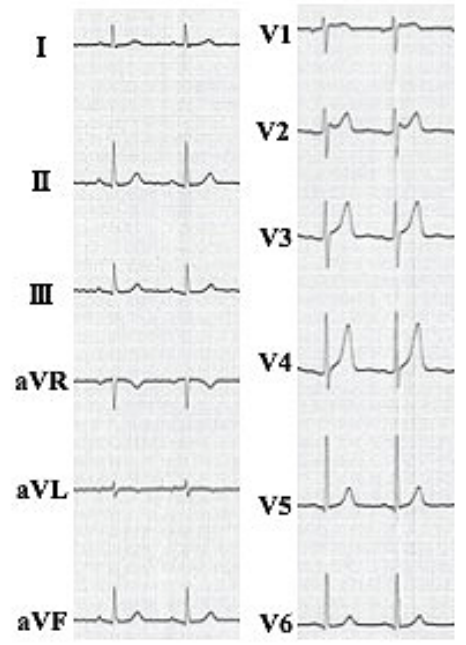

B After 3 minutes

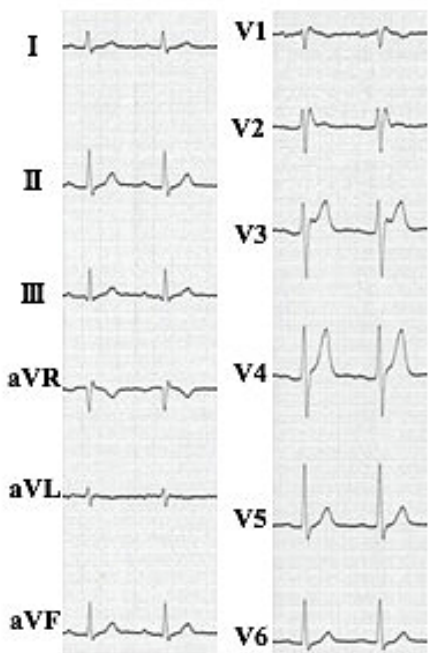

C After 5 minutes

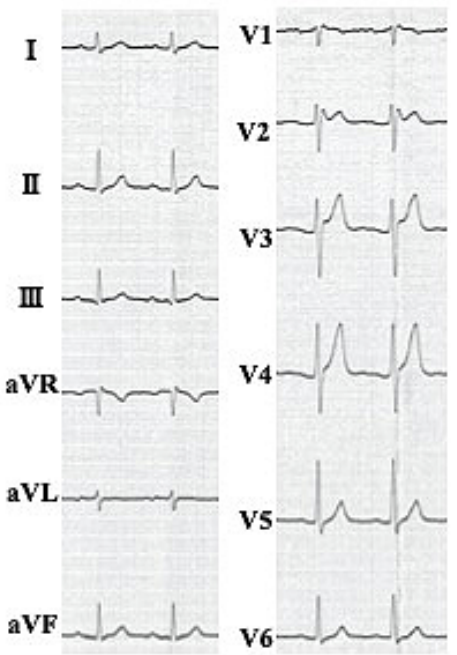

Figure 3. Electrocardiograms during a pilsicainide provocation test. A: Baseline, B: after 3 minutes, and C: after 5 minutes. Drug-provocation test using intravenous pilsicainide of $1 \mathrm{mg} / \mathrm{kg}$ is performed. Although a slight type 1 elevation is observed in V1, the typical Brugada ECG pattern is not induced.

stimulation (PVS) using up to three extra stimuli until S3 to $\mathrm{S} 4$ of 180 milliseconds, with pacing cycle lengths of 400 milliseconds from the right ventricular (RV) apex and RV outflow tract. Coronary angiography showed no stenotic lesions. A drug-provocation test using pilsicainide 1 $\mathrm{mg} / \mathrm{kg}$ intravenously was performed. Although a slight type 1 ST elevation was observed in V1, a typical Brugada-like ECG pattern was not induced (Figure 3).
Because the VF storm was considered to have been caused by reversible hypercalcemia due to primary hyperparathyroidism, a cardioverter-defibrillator (ICD) was not implanted. The patient has remained asymptomatic up to 12-month follow-up. 


\section{Discussion}

There have been a few case reports on the development of VF with prominent $\mathrm{J}$ waves due to hypercalcemia. $^{2-4)}$ Of the case reports, one case was concomitant with drug-provoked Brugada syndrome. . $^{4}$ The present case demonstrated, for the first time, the efficacy of ISP infusion for the secondary $\mathbf{J}$ wave syndrome due to hypercalcemia; ISP was effective not only for the prevention of $\mathrm{VF}$ but also for the disappearance of the prominent $\mathrm{J}$ waves and Brugada-like ECG pattern.

Hypercalcemia was associated with prolongation of both the PR interval and QRS duration, with shortening of the QT interval and J point elevation. ${ }^{5)}$ In addition, hypercalcemia has been reported to be a cause of J wave syndrome and acquired Brugada ECG pattern or phenocopies. ${ }^{1)}$ Concerning arrhythmogenicity, hypercalcemia facilitates re-entry by shortening the action potential, decreasing conduction velocity, and facilitating delayed afterdepolarizations. ${ }^{6}$

ICD implantation is usually recommended for the secondary prevention of VF episodes, but an ICD was not implanted for the following reasons: 1) the patient had no family history of sudden death; 2) after normalization of the serum calcium level, the $\mathrm{J}$ waves and Brugada-like ECG pattern disappeared and VF did not recur; 3) aggressive PVS during the EPS did not induce ventricular tachyarrhythmias; and 4) the drug-provocation test using intravenous pilsicainide did not show the typical Brugada ECG pattern. Although lateen Brugada syndrome could not be denied, it was considered that the present patient exhibited secondary J wave syndrome due to temporarily severe hypercalcemia. The patient remained asymptomatic during 12-month follow-up, but careful clinical and electrocardiographic follow-up seems mandatory.

\section{Disclosure}

Conflicts of interest: None.

\section{References}

1. Antzelevitch C, Yan GX, Ackerman MJ, et al. J-wave syndrome expert consensus conference report: Emerging concepts and gaps in knowledge. J Arrhythmia 2016; 32: 315-39.

2. Kiewiet RM, Ponssen HH, Janssens ENW, Fels PW. Ventricular fibrillation in hypercalcaemic crisis due to primary hyperparathyroidism. Neth J Med 2004; 62: 94-6.

3. Wu LS, Wu CT, Hsu LA, Luqman N, Kuo CT. Brugada-like electrocardiographic pattern and ventricular fibrillation in a patient with primary hyperparathyroidism. Europace 2007; 9: 1724.

4. Zeb M, McKenzie DB, Naheed B, Gazis T, et al. Hypercalcaemia and a Brugada-like ECG: an independent risk factor for fatal arrhythmias. Resuscitation 2010; 81: 1048-50.

5. Sonoda K, Watanabe H, Hisamatsu T, et al. High frequency of early repolarization and Brugada-type electrocardiograms in hypercalcemia. Ann Noninvasive Electrocardiol 2016; 21: 30-40.

6. Kolb C, Lehmann G, Schreieck J, Ndrepepa G, Schmitt C. Storms of ventricular tachyarrhythmias associated with primary hyperparathyroidism in a patient with dilated cardiomyopathy. Int J Cardiol 2003; 87: 115-6. 